\title{
Characterization of residential household dust from Shanghai by particle size and analysis of organophosphorus flame retardants and metals
}

Li Li ${ }^{1,2}$, Yanling Qiu ${ }^{1,2^{*}}$ (D, Åsa Gustafsson ${ }^{3}$, Annette M. Krais ${ }^{4}$, Jana M. Weiss ${ }^{5}$, Thomas Lundh ${ }^{4}$ and Åke Bergman ${ }^{1,3,5}$

\begin{abstract}
Background: Physical and biological properties of dust particles might affect the availability and distribution of chemicals associated to indoor dust; however it has not been adequately examined. In this study, household dust from Shanghai was fractionated into five particle sizes and size distribution, morphology, surface area, organic matter, microorganisms, elemental composition, metals and organophosphorus flame retardants (OPFRs) compositions were characterized. Also, household dust samples from Stockholm that has previously been characterized were included in the analysis of OPFRs for comparison.

Results: The respirable fraction had a yield of $3.3 \%$ in mass percentage, with a particle size of $2.22 \pm 2.04 \mu \mathrm{m}$. As expected, both metals and OPFRs concentrations increased with decreased particle size. Al and Fe dominated (6687\%) followed by the concentrations of $\mathrm{Zn}(5-14 \%)$ and $\mathrm{Ga}(1.8-5 \%)$ of the sum of 16 metals in the dust. The concentrations of OPFRs in Shanghai dust ranged from 5.34 to $13.7 \mu \mathrm{g} / \mathrm{g}$ (median: $7.21 \mu \mathrm{g} / \mathrm{g}$ ), compared to household dust from Stockholm that ranged from 16.0 to $28.3 \mu \mathrm{g} / \mathrm{g}$ (median: $26.6 \mu \mathrm{g} / \mathrm{g}$ ). Tris(2-chloroisopropyl) phosphate (TCIPP) and tris(2-chloroethyl) phosphate (TCEP) dominated in Shanghai dust samples while tris(2-butoxyethyl) phosphate (TBOEP) dominated in dust from Stockholm homes.

Conclusion: The results showed that mass percentage for each particle size fraction was not evenly distributed. Furthermore, the particle-bound microorganisms and OPFRs increased with decreased particle size, whereas metals had the highest concentrations at specific dust sizes. Therefore, it is essential to select the proper particle size in order to assess any specific human exposure study to indoor pollutants.
\end{abstract}

Keywords: Organophosphorus flame retardants, Metals, Size distribution, Particle characterization, Household dust

\section{Background}

People spend most of their time indoor. In China, adults stay on average $20.0 \mathrm{~h} /$ day indoor and children $21.7 \mathrm{~h} /$ day [1]. Indoor air pollution cause premature death of

\footnotetext{
*Correspondence: ylqiu@tongji.edu.cn

${ }^{1}$ Key Laboratory of Yangtze River Water Environment, College of Environmental Science and Engineering, Tongji University, Shanghai 200092, China

Full list of author information is available at the end of the article
}

3.8 million people annually, due to pneumonia, stroke, ischaemic heart disease, chronic obstructive pulmonary disease and lung cancer [2-4]. Household dust contamination may serve as a proxy for indoor air pollution of semi-volatile organic chemicals (SVOCs) [5]. In contrast to volatile chemicals, the SVOCs adsorb to surfaces of particulates, thus household dust might serve as a sink for indoor environmental contaminants [5]. Of the SVOCs, organophosphorus flame retardants (OPFRs) applied in household electronics, building materials, 
flooring and furniture et al. may migrate from the materials and partition among air, suspended particles and settled dust [6]. Ubiquitous presence of OPFRs in household dust has been reported [7] and toxicological studies have shown that OPFRs have the potential to cause adverse endocrine and reproductive effects in animal studies [8]. Human exposure to hazardous chemicals may occur by ingestion, inhalation and dermal contact to household dust. Since infants and children are the most vulnerable population to hazardous chemicals, it is important to lower their exposures as far as possible. The vulnerability is due to a greater intake of chemicals relative to their body weight as well as due to a rapid cell proliferation with growing organs and developing neurological system [9]. It is also important to lower indoor exposures to women in child-bearing ages to minimize the placental transfer of hazardous chemicals to the foetus.

Hence, to perform a thorough risk assessment for exposure to indoor air pollutants, it is crucial to assess physical, chemical and biological properties of household dust. Factors that are important to take into considerations are: (i) to determine the dust particle sizes which are relevant for each exposure pathways, i.e. analyse the size fraction that adhere to the skin and can be ingested by a hand-to-mouth activities as well as a size fraction that is respirable; (ii) to characterize the dust morphology since it impacts the inhalation and ingestion exposure risk assessment. Dust agglomeration changes the aerodynamic diameter, which has an impact on its deposition in different regions of the airways [10]. Also, dust morphology may imply dust sources and hence change chemical distribution among dust size fractions [11]; (iii) to determine particulate surface area, pore volume and organic matter of dust which are all indicators of adsorption capacity of SVOCs and known to influence on the desorption of SVOCs in the human body [12, 13]; (iv) to acknowledge the distribution of metals, microorganisms and trace organic compounds since they are generally not uniformly distributed among various particle sizes.

Shanghai is a large city with a population of 24 million and a significant traffic density by vehicles, boats and aircrafts [14]. The composition of household dust is a mirror of products, materials and goods present in the homes, but also still may be affected by outdoor sources. Therefore, characterization of household dust is important for accurate risk assessment of biological and chemical pollutants from outdoor and indoor environments. In this study, a comprehensive comparison between different size fractions of household dust from Shanghai has been performed including: (i) physical characterization, such as dust particle size and particle size distribution, morphology and specific surface area; (ii) inorganic chemical characterization including core- and surface elemental composition and metal content; (iii) organic characterization, such as organic matter and presence of microorganisms; and (iv) chemical profiling of OPFRs levels on the different size fractions of dust from Shanghai (China) and an additional dust sample from Stockholm (Sweden) which has been previously characterized [10]. To our knowledge, this is the first report on a comprehensive physical, chemical and biological characterization of household dust from Shanghai.

\section{Materials and methods}

\section{Collection of household dust}

The household dust was obtained through normal use of vacuum cleaning by household residents in Shanghai. All the sampling apartments locate in urban area of Shanghai and no floor polishing liquids were applied during the sampling period. In total two batches of household dust were processed. Batch 1 consisted of dust from 10 pooled vacuum cleaner bags from 10 houses that were accumulated in the period from January to April in 2017. Batch 2 consisted of dust from four pooled vacuum cleaner bags that were collected from another four houses accumulated during the same period as Batch 1 . Both batches were processed to different size fractions as described below. Batch 1 is the origin of the fractions $F 1$ (190$390 \mu \mathrm{m}), F 2(75-190 \mu \mathrm{m}), F 3(25-75 \mu \mathrm{m}), F 4$ (cyclone, $4-25 \mu \mathrm{m})$ and $F 5$ (respirable fraction, $<4 \mu \mathrm{m}$ ). Due to very low yield of $F 5$ and hence too little material to carry out all the analyses, additional vacuum cleaner bags were collected that obtained Batch 2. Batch 2 is the origin to the extended respirable fraction $(F 5 \mathrm{e})$.

\section{Sieving of household dust}

In order to separate the household dust to different size fractions, a two-step process of sieving was carried out which has been described elsewhere [10]. In the second step when obtaining the respirable fraction, the dust was stuck in the twilled weave mesh $(25 \mu \mathrm{m})$ and could not be vacuumed out by the industrial vacuum cleaner, resulting in limited dust of the respirable fraction $F 5$ for Batch 1. Therefore, step two was modified for Batch 2 to increase the yield for the respirable fraction that is the twilled weave mesh $(25 \mu \mathrm{m})$ was substituted to the plain weave mesh $(25 \mu \mathrm{m})$.

The dust samples, always kept in glass bottles, were after fractionation homogenized by rotation overnight prior to characterization and analysis. For all analyses only one replicate was used, except for determination of dry matter and loss of ignition and analysis of OPFRs, for which three replicates were used.

A batch of Stockholm household dust was collected in a previous study which has gone through the same sieving process as for Batch 1 [10]. The corresponding fractions 
are referred to StF1 $(190-390 \mu \mathrm{m})$, StF2 $(75-190 \mu \mathrm{m})$, StF3 $(25-75 \mu \mathrm{m})$, StF4 (cyclone, 4-25 $\mu \mathrm{m})$ and StF5 (respirable fraction, $<4 \mu \mathrm{m})$.

An overview of which batches and size fractions that has been used to each analysis is presented in Additional file 1: Table S1.

\section{Size distribution of the household dust}

The size distribution of the household dust was determined using a cascade impactor (Marple Andersen, EnVirREC AB, Sweden). The PreciseInhale system (Inhalation Sciences Sweden AB, Stockholm, Sweden) was used to measure the aerodynamic size distribution with the cascade impactor at a flow rate of $2 \mathrm{~L} / \mathrm{min}$ following aerosolizing of the household dust as previously described in the articles by Selg et al. $[15,16]$. The mass median aerodynamic diameter (MMAD) and the geometric standard deviation (GSD) were calculated based on the mass of dust deposited on the nine stages in the impactor. Triplicate samples were analysed to test the particle size of the respirable fraction.

\section{Scanning electron microscopy (SEM)}

The household dust particle size, morphology and tendency to agglomerate were characterized by field emission SEM (Carl Zeiss Merlin) using a backscatter electron detector. Briefly, the household dust particles were added on an adhesive tape mounted on an aluminium stub and coated with $10 \mathrm{~nm}$ platinum (Q150T ES, West Sussex, UK). The specimens were analysed in an Ultra 55 field emission scanning electron microscope (Zeiss, Oberkochen, Germany) at $5 \mathrm{kV}$ using a secondary electron detector. Duplicates were analysed for each dust sample.

\section{Determination of specific surface area}

The specific surface area of the household dust was determined with the Brunauer-Emmett-Teller (BET) method utilized by a Micrometrics ASAP2020 volumetric adsorption analyser. The household dust sample was treated under vacuum condition at a temperature of $60{ }^{\circ} \mathrm{C}$ for $10 \mathrm{~h}$. The isotherms of nitrogen adsorptiondesorption were recorded at liquid-nitrogen temperature (77 K) for the dust sample. The specific surface areas of the adsorbent dust were then calculated, according to the BET method, from the recorded data in the range of $P / P 0=0.05-0.15$. Duplicates were analysed for each dust sample to acquire the specific surface area.

\section{Elemental composition determined by X-ray powder diffraction (XRD)}

The mineralogical composition of the dust was determined by XRD analysis. Briefly, XRD patterns were measured on a D-8 Advance X-ray diffractometer (Bruker-AXS, Germany) with $\mathrm{Cu} \mathrm{K} \alpha$ radiation operated at a voltage of $40 \mathrm{kV}$ and a current of $40 \mathrm{~mA}$. Processing of the spectra was accomplished with the X'Pert High Score Plus (version 3.0e) software. Triplicate samples were carried out for XRD analysis.

\section{Elemental composition determined by X-ray photoelectron spectroscopy (XPS)}

The elemental composition of the outer surface layer of the dust was determined by XPS analysis. The description for XPS analyses on household dust has previously been described [10]. Briefly, a Kratos Axis Ultra DLD electron spectrometer using monochromated $\mathrm{Al} \mathrm{K \alpha}$ source operated at $150 \mathrm{~W}$ was used to collect the XPS spectra. An analyser pass energy of $160 \mathrm{eV}$ was used for acquiring wide spectra and a pass energy of $20 \mathrm{eV}$ for individual photoelectron lines. A spectrometer charge neutralization system was used to stabilize the surface potential. The binding energy scale was referenced to the $\mathrm{C} 1 \mathrm{~s}$ line of aliphatic carbon, set at $285.0 \mathrm{eV}$. Processing of the spectra was accomplished with the Kratos software. Duplicates were conducted for each dust sample to XPS analysis.

\section{Metal determination by inductively coupled plasma mass spectrometry (ICP-MS)}

Dust was analysed for $\mathrm{Al}, \mathrm{Fe}, \mathrm{Ba}, \mathrm{As}, \mathrm{Cd}, \mathrm{Cr}, \mathrm{Co}, \mathrm{Cu}, \mathrm{Pb}$, $\mathrm{Mn}, \mathrm{Ni}, \mathrm{Tl}, \mathrm{U}, \mathrm{Ga}, \mathrm{V}$ and $\mathrm{Zn}$. The mass of $10 \mathrm{mg}$ dust was added to $10 \mathrm{~mL}$ nitric acid $(2 \% \mathrm{v} / \mathrm{v})$. After centrifugation the metal concentrations were determined in peak jumping mode by ICP-MS (iCAP Q, Thermo Scientific, Bremen, $\mathrm{GmbH}$ ) in collision cell mode with kinetic energy discrimination using helium as collision gas. For each dust sample, triplicates were analysed. The detection limits were calculated as three times the standard deviation of the blank and were $0.01 \mu \mathrm{g} / \mathrm{L}(\mathrm{Cd}, \mathrm{Co}, \mathrm{Tl}, \mathrm{V}$, $\mathrm{U}), 0.02 \mu \mathrm{g} / \mathrm{L}(\mathrm{As}, \mathrm{Cr}, \mathrm{Ni}), 0.05 \mu \mathrm{g} / \mathrm{L}(\mathrm{Pb}), 0.14 \mu \mathrm{g} / \mathrm{L}(\mathrm{Cu})$, $0.22 \mu \mathrm{g} / \mathrm{L}(\mathrm{Al})$ and $0.35 \mu \mathrm{g} / \mathrm{L}(\mathrm{Zn})$.

The enrichment factor (EF) has been used to differentiate anthropogenic sources from natural origin, as well as to assess the degree of influence by human activity, which is calculated as Eq. (1) [17]:

$$
\mathrm{EF}=\left[C_{\text {element }}^{\text {dust }} / C_{\text {reference }}^{\text {dust }}\right] /\left[C_{\text {element }}^{\text {crust }} / C_{\text {reference }}^{\text {crust }}\right],
$$

where $C_{\text {element }}^{\text {dust }}$ or $C_{\text {reference }}^{\text {dust }}$ is the concentration of a target element or reference element in one dust sample; $C_{\text {element }}^{\text {crust }}$ or $C_{\text {reference }}^{\text {crust }}$ is the background concentration of a target element or reference element in the crust from the same region. In this study, $\mathrm{Mn}$ is a conservative element and was selected as the reference element. The background concentration of reference element in crust in Shanghai 
was derived from China National Environmental Monitoring Center [18].

\section{Determination of organic matter content and water content}

The dry matter residue and organic matter content were determined by ignition residue, conducted according to standardized procedures in "Determination of dry matter and ignition residue in water, sludge and sediment" (SS 028113) [19]. Triplicates for each sample were analysed for the test of organic matter content and water content.

\section{Determination of microorganisms in the household dust}

The determination of microorganisms was performed according to standard procedures by Eurofins Pegasuslab AB (Uppsala, Sweden). Briefly, the taxonomical determination (PSMB12B) of both bacteria and fungi species were done according to Arx and Bergey's systematics $[20,21]$. The proportion of cultivable bacteria and fungi (colony-forming unit [CFU]/g) were determined according to the method by Jensen [22]. The total number of bacteria and fungi (PSMB13) was determined with some modification based on the methods found in the papers [23-25]. For each dust sample, duplicates were analysed.

\section{OPFRs determination in the household dust from Shanghai and Stockholm}

All organophosphate ester individual standards, including tris(2-chloroethyl) phosphate (TCEP), tris(2-chloroisopropyl) phosphate (TCIPP), tris(1,3-dichloroisopropyl) phosphate (TDCIPP), tris-(butyl) phosphate (TBP), tris(2-butoxyethyl) phosphate (TBOEP), tris(phenyl) phosphate (TPhP) and tris(methylphenyl) phosphate (TMPP) as well as four internal standards (IS; TCEP-d12, TDCIPP-d15, TBP-d27 and TPhP-d15) were purchased from TRC Chemicals (Toronto, Canada). Hexane, acetone, ethyl acetate and methanol were purchased from Sigma Aldrich (Germany).

Dust samples were extracted by ultrasonication and purified by Florisil cartridges. Instrumental analysis was performed on a Waters UPLC-MS/MS system. Detailed information on the sample preparation, instrumental analysis, quality assurance and quality control, limit of detection and limit of quantification is provided in Additional file 1: OPFRs determination and Table S2-S3.

\section{Statistical analysis}

Statistical analysis of the data was performed using Microsoft Excel 2013 and IBM SPSS Statistics (version 23). Nonparametric test was performed for testing difference between OPFRs in the analysed household dust from Shanghai and Stockholm. A $p$ value $<0.05$ was taken to indicate statistical significance.

\section{Results and discussion}

The collection of vacuum cleaner bags is beneficial to obtain large quantity of dust compared to passive sampling methods [26]. This method is particularly useful for the isolation of the respirable particle fraction of household dust, as large quantities of household dust are required to be successful in isolation of material for the analyses performed herein. Still, this technique has certain disadvantages, such as not properly collecting some fine and ultrafine dust particles from the vacuum cleaning bags and further, contamination from inner parts of commercial vacuum cleaner bags and vacuum cleaners may occur [26]. In addition, there were no prescribed instructions to the users of the vacuum cleaners regarding the models for the sampling of the residences, hence there might be slight deviation regarding the characterization of the fraction containing the smallest particles isolated in this experiment.

\section{Yield of each size fraction}

A total of 10 vacuum bags containing $1.1 \mathrm{~kg}$ crude household dust and four vacuum cleaner bags containing $0.3 \mathrm{~kg}$ crude household dust were collected for Batch 1 and Batch 2, respectively. The relative distribution of the content of mass isolated in each size fraction for the two batches of household dust from Shanghai is presented in Fig. 1, and compared to the corresponding result from the previous study of dust from Stockholm [10]. The yields showed a bimodal distribution, with the mass percentage peaked in fraction $25-75 \mu \mathrm{m}$ for Batch 1 or cyclone $4-25 \mu \mathrm{m}$ for Batch 2 and fraction $>2000 \mu \mathrm{m}$. As stated above, there was a significant loss of material in the second step during the sieving of Batch 1 , resulting in a very low yield $(0.05 \%)$ for the respirable fraction. An increased yield (3.3\%) for the respirable fraction of Batch 2 was obtained which may be attributed to method modifying and different sample pools.

The relative mass distribution of the content isolated for each size fraction is rather similar for Batch 1 from Shanghai and Stockholm (Batch 3) while Batch 2 (Shanghai) is significantly different from Batch 1 and 3 . The processing of dust for Batch 2 resulted in an increased yield for the four size fractions below $190 \mu \mathrm{m}$ compared to Batch 1. For the respirable, cyclone, 25-75 $\mu \mathrm{m}$ and 75-190 $\mu \mathrm{m}$ fractions the yields were 68 times, 4 times, 1.6 times and 1.2 times higher, respectively, in Batch 2 compared to Batch 1. The higher yield in Batch 2 compared to Batch 1 in respirable fraction was probably the method of generating this fraction, and in cyclone, 25-75 $\mu \mathrm{m}$ and $75-190 \mu \mathrm{m}$ fractions the reason might be 


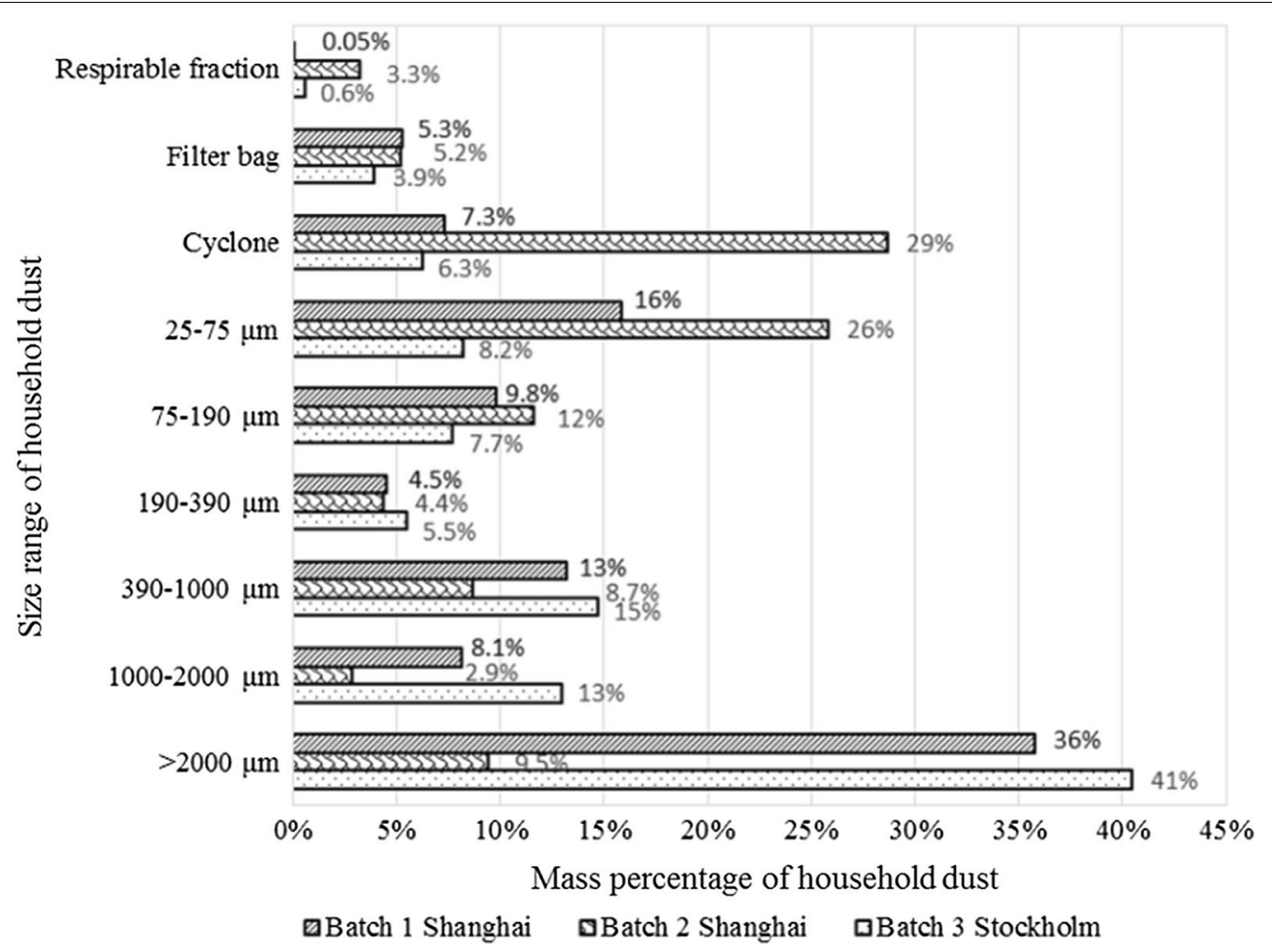

Fig. 1 Relative yield (mass percentage) of household dust for each size fraction from Shanghai (Batch 1 and 2). A comparison with the previously characterized Stockholm household dust (Batch 3) is also included [10]

more high-density material i.e. minerals was collected in Batch 2.

\section{Particle size distribution of the respirable fraction}

The respirable size fraction consists of the inhaled airborne material that penetrates to the lower gas exchange region of the lung [27]. Particles with a diameter below $4 \mu \mathrm{m}$ were defined as respirable fraction [28]. In this study, the particle size of the respirable fraction (F5e) was measured as $2.22 \mu \mathrm{m}$ mass median aerodynamic diameter (MMAD) with a geometric standard deviation (GSD) of $2.04 \mu \mathrm{m}$ (Additional file 1: Figure S1). The particles were slightly smaller compared to dust particles from Stockholm that were obtained by the unmodified method $(3.73 \pm 0.15 \mu \mathrm{m}$ MMAD with a GSD of $2.29 \pm 0.03 \mu \mathrm{m})$ [10].

\section{Morphology and agglomeration}

Differences in size, morphology and agglomeration was observed by SEM. Figure 2A shows that dust fraction $F 1$ contained flake-like and fibrous particles, while dust fractions $F 2$ and $F 3$ contained rod-like and spherical particles (Fig. 2B, C). The morphology was different compared with a similar particle size fraction $(20.2 \pm 17.9 \mu \mathrm{m})$ reported from Beijing offices dust, where flaky particles were described [29]. The author speculated that this particle fraction was weathered fragments of polymer matrix. Little agglomeration for the three larger particulate fractions was observed in the present study. In F4 and $F 5 \mathrm{e}$, crystalline particles in angular shape and floccules were agglomerated to form larger particles (Fig. 2D, E). According to Yang and colleagues [30], the angular particles might result from outdoors and might not have experienced long-term abrasion. In the respirable particle size from Sweden that was obtained by the same method, SEM pictures showed similarities in the agglomeration, but different particle shape [10]. It is reasonable to have differences in both morphology and agglomeration potentials of the particulates from Shanghai and Stockholm due to the environmental differences between the sites.

\section{Specific surface area and pore volume}

The specific surface area and pore volume for the particle fractions F2, F3, F4 and F5e are listed in Table 1. For comparison, silica particles in sizes of $<75 \mu \mathrm{m}$ and the respirable fraction are also presented in Table 1 . The surface area for fractions $F 2$ and $F 3$ were similar, with values of $0.6 \mathrm{~m}^{2} / \mathrm{g}$. The surface area increased with decreasing 

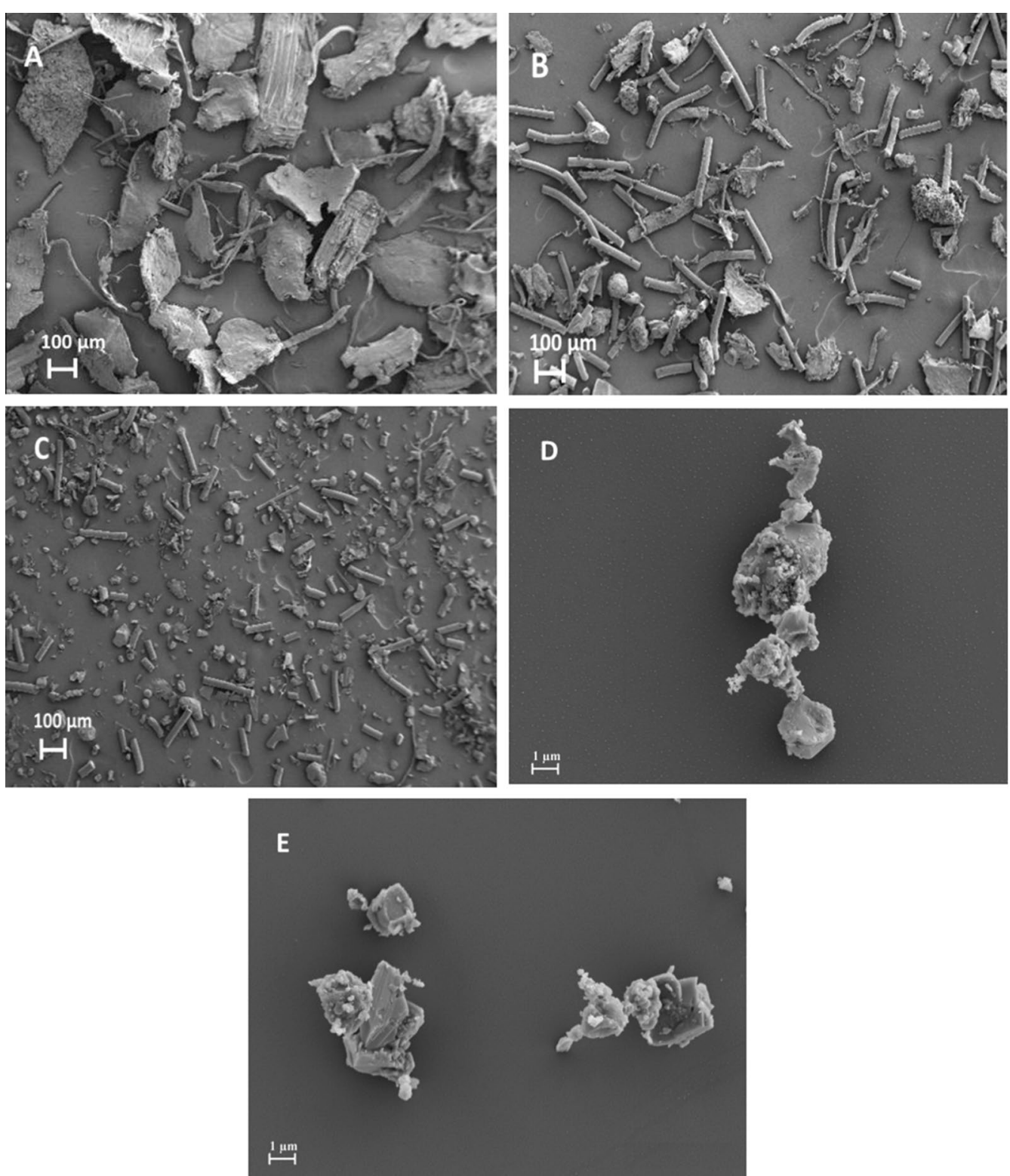

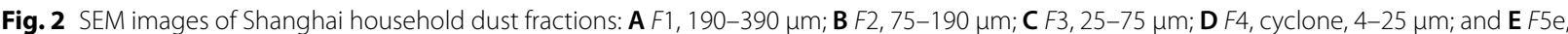
$2.22 \pm 2.04 \mu \mathrm{m}$

Table 1 Specific surface area and pore volume in fractions of Shanghai household dust and silica

\begin{tabular}{lll}
\hline Particle size & $\begin{array}{l}\text { Surface area }\left(\mathbf{m}^{\mathbf{2}} / \mathbf{g}\right. \\
\text { dust })\end{array}$ & $\begin{array}{l}\text { Pore volume } \\
\left(\mathbf{c m}^{3} / \mathbf{g} \text { dust }\right)\end{array}$ \\
\hline F2 & 0.60 & $2.13 \times 10^{-3}$ \\
F3 & 0.61 & $2.13 \times 10^{-3}$ \\
F4 & 0.99 & $3.27 \times 10^{-3}$ \\
F5e & 4.48 & $2.21 \times 10^{-2}$ \\
Silica $<75 \mu \mathrm{m}$ & 0.60 & $1.13 \times 10^{-3}$ \\
Silica respirable fraction & 2.50 & $5.86 \times 10^{-3}$ \\
\hline
\end{tabular}

F2: 75-190 $\mu \mathrm{m}$, F3: 25-75 $\mu \mathrm{m}$, F4: cyclone 4-25 $\mu \mathrm{m}$ and F5e: $2.22 \pm 2.04 \mu \mathrm{m}$ particle size, as confirmed by other studies [12, 29]. Relevant data was reported on a composite dust from Beijing offices where they separated the dust to thirteen size fractions of which the smallest size fraction was $5.64 \pm 6.78 \mu \mathrm{m}$ and the surface area was $4.9 \mathrm{~m}^{2} / \mathrm{g}$ [29]. The surface area for the respirable fraction of Swedish household dust was reported $2.5 \mathrm{~m}^{2} / \mathrm{g}$ [10]. The surface area in the respirable fraction of Shanghai household dust in the present study was about the same as that in Beijing office dust, and surface areas of both Chinese dust samples were higher compared to the Swedish dust. 
The pore volume for fractions $F 2$ and $F 3$ was measured the same value of $2.13 \times 10^{-3} \mathrm{~cm}^{3} / \mathrm{g}$, then pore volume was observed to increase with decreasing particle size. In contrast, there was no inverse relation between pore volume and particle size in one study reported from Shanghai [31]. In that study, a pooled dust sample from air conditioner filters from dining halls in Shanghai University was separated into five sizes and the pore volume was comparable in all the fractions [31].

\section{Mineralogical composition}

The most abundant minerals of particle fraction $F 1$ $(190-390 \mu \mathrm{m})$, as determined by X-ray diffraction, were silicon dioxide (quartz) and barium succinate, while in $F 2$ (75-190 $\mu \mathrm{m})$, no commonly reported minerals could be identified. In $F 3(25-75 \mu \mathrm{m})$ the major components were quartz and dolomite, whereas the most abundant minerals of both particle fractions F4 (cyclone, 4-25 $\mu \mathrm{m}$ ) and F5e $(2.22 \pm 2.04 \mu \mathrm{m})$ were found to be quartz and calcite. The presence of quartz and calcite has earlier been demonstrated in residential household dust from Sweden
[10, 32] and dust from Danish offices [32]. In a Canadian household dust study, it was found that quartz and feldspar dominated, followed by lithic fragments and carbonate minerals (including calcite, dolomite and chalk) in all six cities studied [33].

\section{Surface elemental composition}

Elemental analysis of the particle surface in $F 2, F 3$ and F4 revealed that it consisted mainly of carbon (73-77\%), oxygen (17-20\%) and nitrogen (1.6-2.0\%) (Fig. 3). The respirable fraction $F 5$ e contained less carbon (57\%), more oxygen (29\%) and similar amounts of nitrogen (1.5\%), compared to the larger fractions. Carbon was the most abundant as aliphatic compounds $(\mathrm{C}-\mathrm{H})$ in all size fractions but also carbon compositions of $\mathrm{C}-\mathrm{O}, \mathrm{C}-\mathrm{N}, \mathrm{C}-\mathrm{S}$ and $-\mathrm{COOH}$ were present. Thiol groups were also present in lower concentrations, close to detection limit of XPS (0.1 at.\%). The main inorganic element found in all four size fractions was silicon, and its binding energy was characteristic for silicates or aluminosilicates. Other inorganic elements included sodium, calcium, potassium,

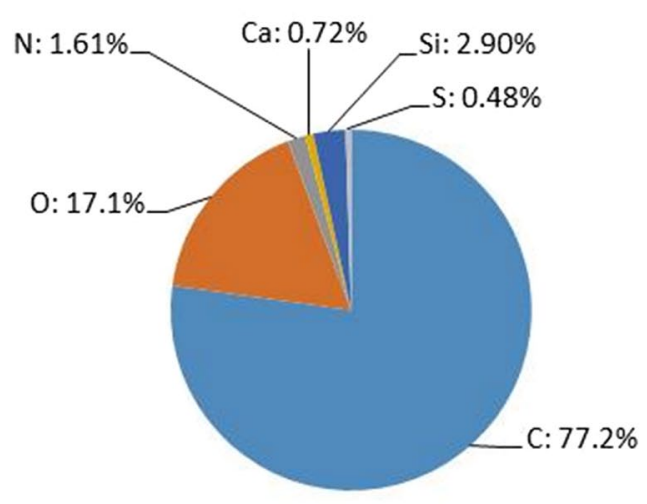

F2

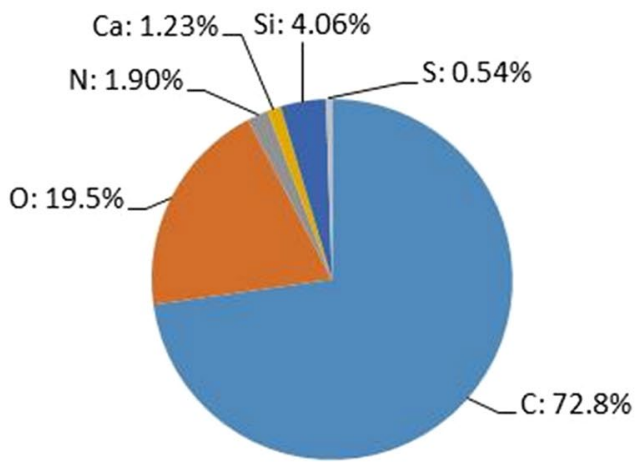

F4

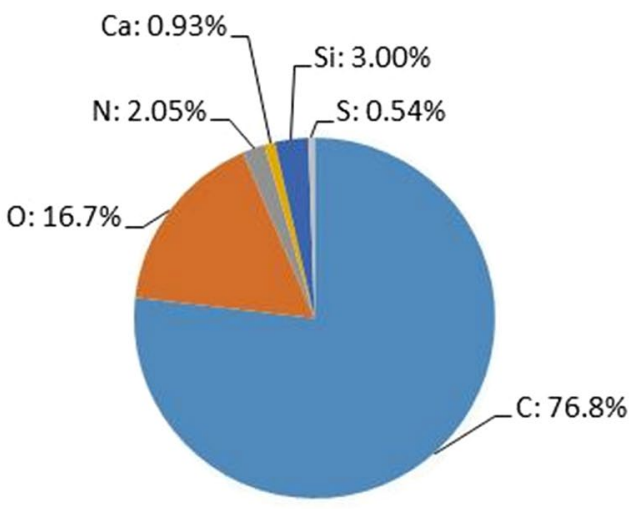

F3

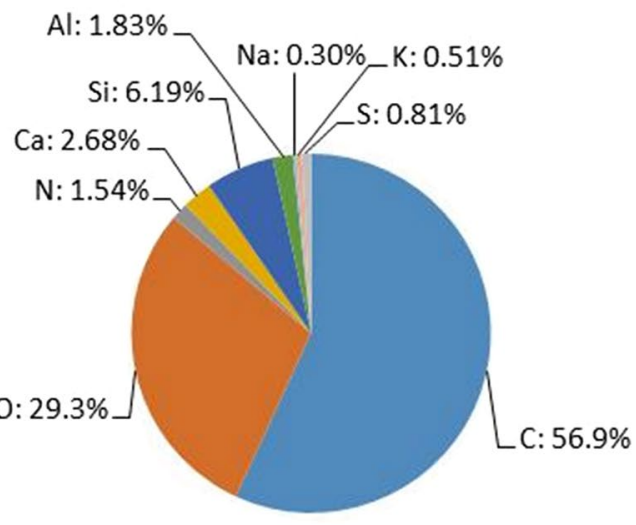

F5e

Fig. 3 Surface elemental composition in Shanghai household dust fractions presented as relative atomic concentration (\%). F2: 75-190 $\mu \mathrm{m}$, F3: 25-75 $\mu \mathrm{m}$, F4: cyclone 4-25 $\mu \mathrm{m}$ and F5e: $2.22 \pm 2.04 \mu \mathrm{m}$ 
silica, sulfate, aluminium and chlorine. The respirable dust fraction $F 5$ e contained more of aluminium compared to the other fractions analysed, and in addition the two fractions $F 4$ and F5e contained a small amount of iron on their surface.

The elemental composition at the surface of the dust from Shanghai and Sweden were similar [10]. Still, some differences were observed in the respirable fraction. The Swedish dust consisted of $78 \%$ of carbon whereas the Shanghai dust consisted of $57 \%$ of carbon. Another difference was the presence of sulfonate groups in Shanghai dust samples, which might come from washing powder or detergents. Further, Shanghai dust contained more iron at the surface.

\section{Metals}

The concentrations of 16 metals in household dust samples from Shanghai were measured (Table 2). The metals were not uniformly distributed among size fractions. For the majority of the metals (except $\mathrm{Ni}, \mathrm{Pb}$ and $\mathrm{Cd}$ ), the concentrations increased as the particle size decreased. For the metals $\mathrm{Ni}, \mathrm{Pb}$ and $\mathrm{Cd}$, the maximum concentrations were determined in fraction $F 3$. Similar results were found in an Austrian household dust, showing that the concentrations of metals decreased with increasing size [34]. Size dependence of metal concentrations is presented in Additional file 1: Figure S2.

Metal concentrations in the present study were close to the concentrations measured in Japanese residences [35].

Table 2 Metal concentrations in various size fractions of household dust from Shanghai

\begin{tabular}{lllll}
\hline $\mathbf{m g} / \mathbf{k g}$ dust & $\boldsymbol{F 2}$ & $\boldsymbol{F 3}$ & $\boldsymbol{F 4}$ & $\boldsymbol{F 5 e}$ \\
\hline $\mathrm{Al}$ & $1.65 \times 10^{3}$ & $2.93 \times 10^{3}$ & $3.81 \times 10^{3}$ & $1.04 \times 10^{4}$ \\
$\mathrm{As}$ & 3.50 & 5.60 & 8.28 & 9.47 \\
$\mathrm{Ba}$ & 276 & 315 & 352 & 367 \\
$\mathrm{Cd}$ & 2.15 & 2.80 & 2.70 & 1.01 \\
$\mathrm{Co}$ & 1.78 & 2.72 & 4.05 & 6.46 \\
$\mathrm{Cr}$ & 16.0 & 20.9 & 23.0 & 26.2 \\
$\mathrm{Cu}$ & 175 & 181 & 206 & 269 \\
$\mathrm{Fe}$ & $1.62 \times 10^{3}$ & $2.92 \times 10^{3}$ & $3.73 \times 10^{3}$ & $6.06 \times 10^{3}$ \\
$\mathrm{Ga}$ & 244 & 283 & 319 & 346 \\
$\mathrm{Mn}$ & 125 & 192 & 242 & 340 \\
$\mathrm{Ni}$ & 41.1 & 54.1 & 39.0 & 42.0 \\
$\mathrm{~Pb}$ & 63.1 & 146 & 143 & 134 \\
$\mathrm{Tl}$ & $\mathrm{n} . \mathrm{d}$. & $\mathrm{n} . \mathrm{d}$. & $\mathrm{n} . \mathrm{d}$. & $\mathrm{n} . \mathrm{d}$. \\
$\mathrm{U}$ & 0.09 & 0.20 & 0.26 & 0.84 \\
$\mathrm{~V}$ & 5.70 & 9.76 & 12.6 & 23.5 \\
$\mathrm{Zn}$ & 695 & 701 & 840 & 955 \\
$\mathrm{~F}$ & & & &
\end{tabular}

F2: 75-190 $\mu \mathrm{m}$, F3: 25-75 $\mu \mathrm{m}$, F4: cyclone 4-25 $\mu \mathrm{m}$ and F5e: $2.22 \pm 2.04 \mu \mathrm{m}$ n.d. not detected
The respirable fractions from our study (F5e) and from Stockholm dust (StF5) [10], both contained $\mathrm{Al}$ as the most abundant metal, while the levels of $\mathrm{Zn}, \mathrm{Cu}, \mathrm{Mn}, \mathrm{Pb}$, $\mathrm{Ni}$ and $\mathrm{Cr}$ were generally higher in Shanghai dust compared to dust from Stockholm [10].

Cesari et al. proposed that a specific element is likely of crustal origin if $\mathrm{EF}<10$, and likely of anthropogenic origin if $\mathrm{EF}>20$. If $10<\mathrm{EF}<20$, it is likely of mixed origin [36]. In the present study, the $\mathrm{EF}$ values of $\mathrm{Ba}, \mathrm{V}, \mathrm{Cr}, \mathrm{Ni}$, $\mathrm{Co}, \mathrm{U}$, As and $\mathrm{Tl}$ in all size fractions were below 6, indicating their natural origin, e.g. soil re-suspension. The EF values for $\mathrm{Al}, \mathrm{Fe}$ and $\mathrm{Ga}$ in all size fractions were greater than 20 , suggesting that these metals were more likely from anthropogenic origin (Fig. 4). EF values in the four particle sizes for $\mathrm{Cd}, \mathrm{Zn}, \mathrm{Cu}$ and $\mathrm{Pb}$ were not all in the same range, indicating the mixed origin for different dust size.

\section{Organic matter}

Organic matter declined with decreasing particle size. The organic matter measured by the loss on ignition of dry matter was $75.8 \pm 0.3 \%, 66.2 \pm 0.2 \%$, and $27.6 \pm 0.3 \%$ for particle fractions $F 2, F 3$ and $F 4$, respectively. The water content also declined as the particle size decreased and it was determined to $3.69 \%, 2.18 \%$ and $1.71 \%$ for $F 2$, $F 3$ and F4, respectively. The organic matter and water content for the respirable fraction $F 5$ e in our study was $42.4 \pm 0.2 \%$ and $2.42 \%$, respectively. In the respirable fraction from the Swedish household dust, the organic matter was $69 \%$ and the water content was $4 \%$ [10]. Organic matter content in household dust may vary greatly between 5 and $95 \%$, as was reviewed by Butte et al. [5].

\section{Microorganisms}

The total number and cultivable number of fungi and bacteria in each size fraction are shown in Additional file 1: Table S4. The total concentration of cultivable fungi in floor dust varied between non-detectable and $10^{6} \mathrm{CFU} / \mathrm{g}$ dust (colony-forming unit $[\mathrm{CFU}] / \mathrm{g}$ ), and the total fungal cell counts reported to be 10 - to 100-fold higher than the cultivable counts assessed in parallel [37]. In the present study, the concentrations of total fungi and cultivable fungi from Shanghai floor dust were quite high. All dust samples were kept in refrigerator after fractionation. However, it is unknown to which extent the time of transport of crude dust and storage in room temperature before fractionation contribute to microorganism growth. Among the fungi, Cladosporium, Streptomyces, Ulocladium, Eurotium, Wallemia, Penicillium, Chrysogenum, Alternaria, Ochraceus grp, Bacillus mycoides, Trichoderma, Aspergillus niger, Aspergillus spp, Dematiaceous hyphomycetes and yeast were detected in most of the samples. Similar result was observed, detecting 


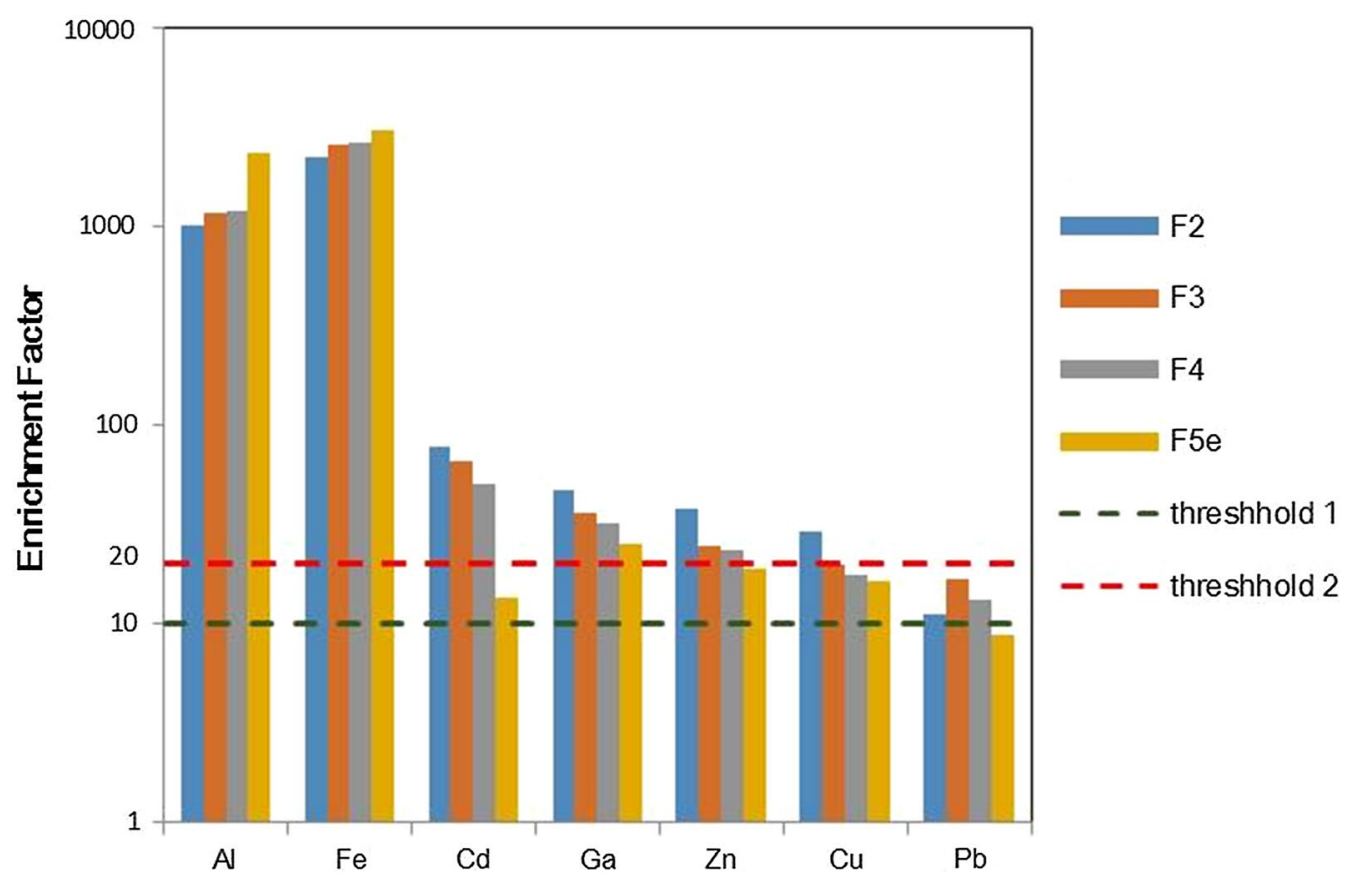

Fig. 4 Enrichment factors (EFs) of metals in household dust fractions. F2: 75-190 $\mu \mathrm{m}, F 3: 25-75 \mu \mathrm{m}$, F4: cyclone 4-25 $\mu \mathrm{m}$ and F5e: $2.22 \pm 2.04 \mu \mathrm{m}$

mainly Aspergillus, Wallemia sebi, Cladosporium as settled fungal species in household dust from Shanghai [38]. Our result was also consistent with the findings that Penicillium, Aspergillus, Cladosporium and about 20 other fungal genera were the most commonly isolated genera from household dust [37]. Concentrations of cultivable bacteria ranged from $1.1 \times 10^{4}$ to $2.1 \times 10^{7} \mathrm{CFU} / \mathrm{g}$ dust with a mean value of $3.4 \times 10^{6} \mathrm{CFU} / \mathrm{g}$ dust in floor dust from Finland households [39]. Cultivable bacteria concentrations in the present floor dust from Shanghai were within the same range.

\section{OPFRs}

OPFRs concentrations and distribution among particle size fractions from Shanghai and Stockholm household dust samples are shown in Fig. 5 and Additional file 1: Table S5. The sum of the analysed OPFRs concentrations in Shanghai household dust ranged from 5.34 to $13.7 \mu \mathrm{g} / \mathrm{g}$ (median: $7.21 \mu \mathrm{g} / \mathrm{g}$ ). The concentrations in Stockholm household dust measured in the present study ranged from 16.0 to $28.3 \mu \mathrm{g} / \mathrm{g}$ (median: $26.6 \mu \mathrm{g} / \mathrm{g}$ ), which is significantly $(p=0.002)$ higher than the value measured in Shanghai household dust. One thing noted is that OPFRs concentrations may be underestimated, e.g. desorption of OPFRs from dust particles may occur under the reduced pressure in the vacuum process and fine and ultrafine dust may be missed collecting during the vacuuming [40].
The levels of OPFRs in household dust from Shanghai and Stockholm were comparable to some studies reported from Europe (Sweden, Spain, Belgium, Romania and Germany), New Zealand and USA (median levels ranging from 3 to $38 \mu \mathrm{g} / \mathrm{g}$ ) [41-47]. Higher levels of OPFRs were reported from Japan (median: $577 \mu \mathrm{g} / \mathrm{g}$ ) [48], whereas lower levels of OPFRs have been reported from Egypt, Philippines and Pakistan (median levels ranging from 0.19 to $0.58 \mu \mathrm{g} / \mathrm{g}$ ) [49-51].

For the composition, the chlorinated OPFRs (TCIPP and TCEP) dominated in Shanghai household dust, while TBOEP was the most abundant in Stockholm household dust. The distribution patterns were similar to the reports from other studies. Chlorinated OPFRs including TDCIPP, TCEP and TCIPP have previously been found to dominate in Shanghai household dust in particles below $500 \mu \mathrm{m}$ [52], and TBOEP has previously been identified as the most abundant compound in Swedish household dust $[53,54]$. The difference of distribution pattern in Shanghai and Stockholm is possibly that TBOEP is frequently added in floor polish and as a plasticizer in rubber and plastics [55]. The low levels of TCEP in Swedish dust could be explained to the prohibition of production in Europe since 1990s, while no general ban on production and usage of any kind of OPFRs is issued in China [56]. Chlorinated OPFRs are of special concern due to their toxicity. They are suspected carcinogens with observed tumour growth 


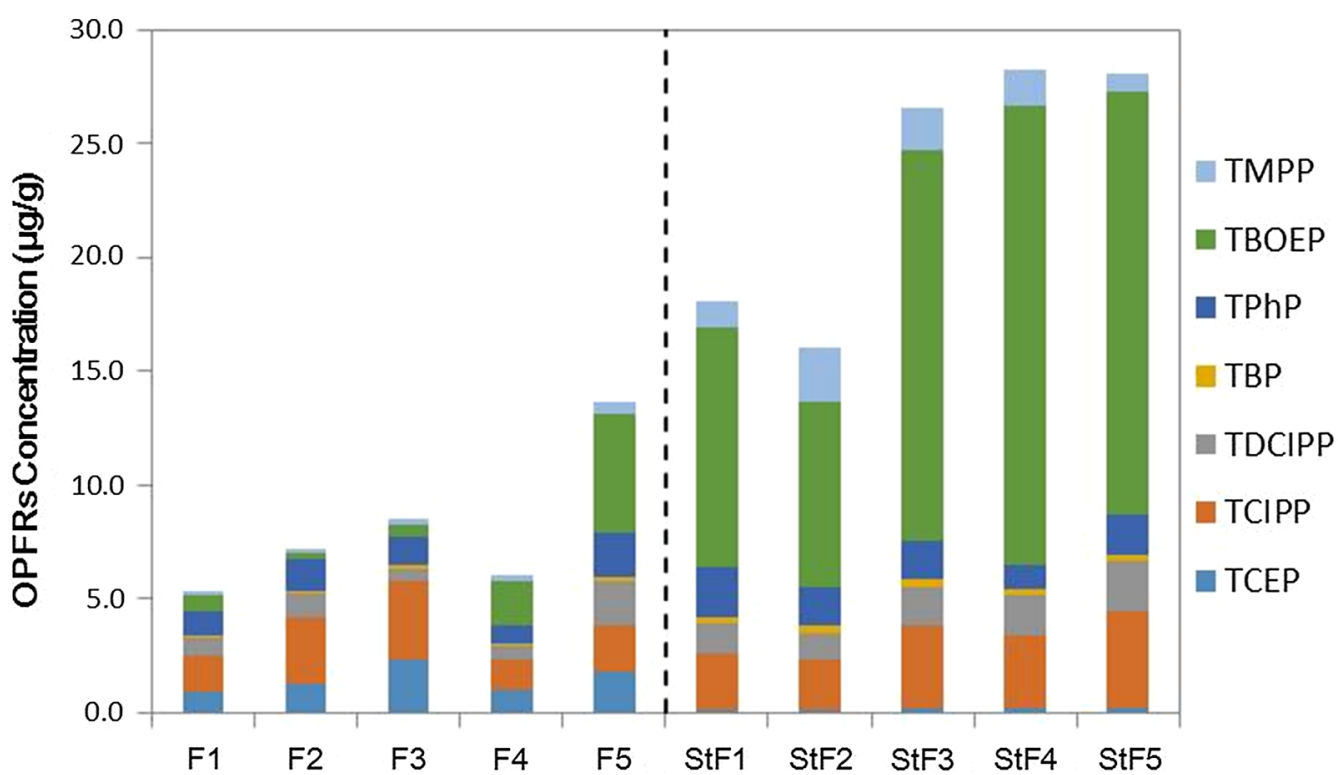

Fig. 5 The distribution of OPFRs levels ( $\mu \mathrm{g} / \mathrm{g}$ dust) in particle size fractions of Shanghai household dust (F1: 190-390 $\mu \mathrm{m}, F 2: 75-190 \mu \mathrm{m}, F 3$ :

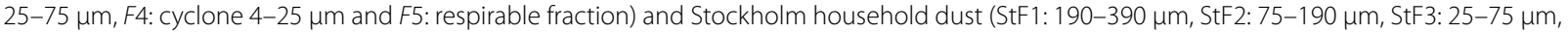
StF4: cyclone 4-25 $\mu \mathrm{m}$ and StF5: respirable fraction)

in kidney, liver and thyroid for TCEP and TCIPP, and in brains and testes for TDCIPP [7, 57]. The levels of TDCIPP in household dust has been associated with altered hormone levels and decreased sperm concentration [58].

Generally the concentrations of OPFRs increased with the decrease of particle size in household dust samples from both Shanghai and Stockholm (Fig. 5). Other studies have reported that the correlation between the concentrations of OPFRs and particle sizes are inconsistent. Indoor dust collected from offices, public microenvironments and cars in Nanjing China were separated into five fractions, and OPFRs concentrations in all three types of dust reported the same correlation with particle size as the present study [12]. In dust from offices in Guangzhou China, the levels of OPFRs levels in fractions $1000-2000 \mu \mathrm{m}$ and 50-100 $\mu \mathrm{m}$ were higher compared to the fractions in between $(500-1000 \mu \mathrm{m}, 250-500 \mu \mathrm{m}$ and $100-250 \mu \mathrm{m})$ [59]. The distribution of OPFRs among particle sizes may depend on multiple factors, which include the migration pathways of OPFRs into dust, compound property and surface area of dust. OPFRs are a group of SVOCs and tend to volatize into air and dust surface area was probably the main influencing factor for the adsorption onto dust instead of total organic matter [12]. As stated above, in the present study Shanghai household dust has an increased surface area following the decrease of particle size, which may explain the increase of OPFRs concentrations with the decrease of particle size.

\section{Conclusion}

Household dust serves as a recipient for both inorganic and organic chemicals as well as for biological components and hence, is a good matrix to study for human external exposure to indoor pollutants. This study reported for the first time the physical, chemical and biological characterization of household dust from Shanghai by particle size.

In this study household dust from Shanghai and Stockholm were compared by applying the same procedures and methodologies which makes the comparison strong. It is observed that the particle size present in the respirable fraction of one composite household dust sample from Shanghai was $2.22 \pm 2.04 \mu \mathrm{m}$, compared to that of $3.73 \pm 2.29 \mu \mathrm{m}$ in one composite Swedish household dust sample. The $\Sigma$ OPFRs concentrations in household dust from Shanghai and Stockholm measured in this study were comparable to most of the studies reported from Europe, New Zealand and USA. The pattern of OPFRs in the present study showed that chlorinated OPFRs (TCIPP and TCEP) dominated in the analysed household dust from Shanghai while TBOEP was the most abundant in the studied Stockholm household dust. Both metal and OPFRs concentrations increased with decreased particle size. 
The selection of a relevant size fraction is of great importance when using dust as a matrix to study exposure of indoor air pollution. The respirable fraction presented in this paper is correlated with inhalation exposure. Considering higher metal concentrations, OPFRs concentrations and microorganism numbers in this fraction, it is important to use relevant fraction for exposure assessment to avoid an underestimation of the risk.

\section{Supplementary information}

Supplementary information accompanies this paper at https://doi. org/10.1186/s12302-019-0279-9.

Additional file 1. Description of OPFRs determination; Tables S1-S5 Figures S1, S2.

\section{Abbreviations}

SVOCs: semi-volatile organic chemicals; OPFRs: organophosphorus flame retardants; TCEP: tris(2-chloroethyl) phosphate; TCIPP: tris(2-chloroisopropyl) phosphate; TDCIPP: tris(1,3-dichloroisopropyl) phosphate; TBP: tris-(butyl) phosphate; TBOEP: tris(2-butoxyethyl) phosphate; TPhP: tris(phenyl) phosphate; TMPP: tris(methylphenyl) phosphate; SEM: scanning electron microscopy; BET: Brunauer-Emmett-Teller; XRD: X-ray powder diffraction; XPS $X$-ray photoelectron spectroscopy; ICP-MS: inductively coupled plasma mass spectrometry; MMAD: mass median aerodynamic diameter; GSD: geometric standard deviation; EF: enrichment factor.

\section{Acknowledgements}

The authors acknowledge Fernando Acevedo and the Acevedo Biochem Consulting for development of the equipment to sieve and process the dust. The facilities and technical assistance of the Umeå Core Facility for Electron Microscopy (UCEM) at the Chemical Biological Centre (KBC), Umeå University; Per Gerde, Maria Malmlöf, Mikael Mikko, Mattias Nowenwik and Ewa Selg at Inhalation Sciences for scientific advice and SEM imaging following aerosolization with the Preciselnhale system; Zoltan Bacsik at the Stockholm University for the specific surface area determination; Zhu Jianyao at Tongji University for the XRD analysis; Andrey Shchukarev at Umeå University for the XRF analysis, and Bo Watz for practical advice at Swetox.

\section{Authors' contributions}

LL collected dust samples, fractionated the dust, measured organic matter content and OPFRs, performed data analysis and wrote the manuscript. YQ was involved in the study design, reviewed the manuscript and is the PI of the NSFC project. ÅG was involved in the study design, took part in the dust sieving, measured the particle size distribution and reviewed the manuscript. AK was involved in the study design, measured the metals and reviewed the manuscript. JW was reviewed the manuscript and provided important perspectives on data interpretation. TL measured the metals and gave suggestions on data interpretation on metals. ÅB was involved in the study design, reviewed the manuscript and is the PI of Swedish research council CHEMSTRRES and MiSSE projects. All authors read and approved the final manuscript.

\section{Funding}

The research was supported by funding from the Swedish Research Council (No. 639-2013-6913, CHEMSTRRES), the Swedish research council FORMAS (No. 210-2012-131, MiSSE) and Natural Science Foundation of China (No. 21777124).

\section{Availability of data and materials}

All data generated or analysed during this study are included in this published article and its Additional files.

\section{Ethics approval and consent to participate}

Not applicable.
Consent for publication

Not applicable.

\section{Competing interests}

The authors declare that they have no competing interests.

\section{Author details}

${ }^{1}$ Key Laboratory of Yangtze River Water Environment, College of Environmental Science and Engineering, Tongji University, Shanghai 200092, China. ${ }^{2}$ Shanghai Institute of Pollution Control and Ecological Security, Shanghai 200092, China. ${ }^{3}$ MTM Research Centre, School of Science and Technology, Örebro University, 70182 Örebro, Sweden. ${ }^{4}$ Division of Occupational and Environmental Medicine, Institution of Laboratory Medicine, Lund University, 22363 Lund, Sweden. ${ }^{5}$ Department of Environmental Science and Analytical Chemistry, Arrhenius Laboratory, Stockholm University, 10691 Stockholm, Sweden.

Received: 1 July 2019 Accepted: 6 December 2019

Published online: 17 December 2019

\section{References}

1. Ministry of Environmental Protection (2016) Exposure factors handbook of Chinese population. Chinese Environmental Science Press, Beijing

2. World Health Organization (2009) Biological indoor air pollutants: dampness and mould. World Health Organization, Geneva

3. World Health Organization (2010) Chemical indoor air pollutants: selected pollutants. World Health Organization, Geneva

4. World Health Organization (2018) Household air pollution and health. https://www.who.int/en/news-room/fact-sheets/detail/household-airpollution-and-health. Accessed 30 June 2019

5. Butte W, Heinzow B (2002) Pollutants in house dust as indicators of indoor contamination. Rev Environ Contam Toxicol 175:1-46

6. Lucattini L, Poma G, Covaci A, de Boer J, Lamoree MH, Leonards PEG (2018) A review of semi-volatile organic compounds (SVOCs) in the indoor environment: occurrence in consumer products, indoor air and dust. Chemosphere 201:466-482

7. Wei GL, Li DQ, Zhuo MN, Liao YS, Xie ZY, Guo TL, Li JJ, Zhang SY, Liang ZQ (2015) Organophosphorus flame retardants and plasticizers: sources, occurrence, toxicity and human exposure. Environ Pollut 196:29-46

8. Hou R, Xu YP, Wang ZJ (2016) Review of OPFRs in animals and humans: absorption, bioaccumulation, metabolism, and internal exposure research. Chemosphere 153:78-90

9. World Health Organization (2011) Summary of principles for evaluating health risks in children associated with exposure to chemicals. https:// www.who.int/ceh/health_risk_children.pdf. Accessed 20 Apr 2019

10. Gustafsson A, Krais AM, Gorzsas A, Lundh T, Gerde P (2018) Isolation and characterization of a respirable particle fraction from residential housedust. Environ Res 161:284-290

11. Wagner J, Ghosal S, Whitehead T, Metayer C (2013) Morphology, spatial distribution, and concentration of flame retardants in consumer products and environmental dusts using scanning electron microscopy and Raman micro-spectroscopy. Environ Int 59:16-26

12. He RW, Li YZ, Xiang P, Li C, Cui XY, Ma LNQ (2018) Impact of particle size on distribution and human exposure of flame retardants in indoor dust. Environ Res 162:166-172

13. Siciliano SD, Laird BD, Lemieux CL (2010) Polycyclic aromatic hydrocarbons are enriched but bioaccessibility reduced in brownfield soils adhered to human hands. Chemosphere 80(9):1101-1108

14. Shanghai Bureau of Statistics (2017) Shanghai statistical yearbook. http:// www.stats-sh.gov.cn/html/sjfb/tjnj/. Accessed 20 Apr 2019

15. Selg E, Acevedo F, Nybom R, Blomgren B, Ryrfeldt A, Gerde P (2010) Delivering horseradish peroxidase as a respirable powder to the isolated, perfused, and ventilated lung of the rat: the pulmonary disposition of an inhaled model biopharmaceutical. J Aerosol Med Pulm Drug Deliv 23(5):273-284

16. Selg E, Ewing P, Acevedo F, Sjoberg CO, Ryrfeldt A, Gerde P (2013) Dry powder inhalation exposures of the endotracheally intubated rat lung, ex vivo and in vivo: the pulmonary pharmacokinetics of fluticasone furoate. J Aerosol Med Pulm Drug Deliv 26(4):181-189 
17. Buatmenard $P$, Chesselet $R$ (1979) Variable influence of the atmospheric flux on the trace-metal chemistry of oceanic suspended matter. Earth Planet Sci Lett 42(3):399-411

18. CNEMC (1990) Background values of soil elements in China. China Environmental Sciences Press, Beijing (in Chinese)

19. SIS SSI (1981) Determination of dry matter and ignition residue in water, sludge and sediment

20. Bergey DH, Buchanan RE, Gibbons NE (1974) Bergey's manual of determinative bacteriology, Pamphlet. Williams \& Wilkins $\mathrm{Co}$, Baltimore

21. Arx JV (1981) The genera of fungi sporulating in pure culture, 3rd edn. Verlag J. Cramer, Vaduz

22. Jensen $V(1962)$ The dilution plate count technique for the enumeration of bacteria and fungi in soil. Zentralblatt fur Bakteriologie und Parasitenkunde II 116:13-32

23. Trolldenier G (1973) The use of fluorescence microscope for counting soil microorganisms. In: Bulletins from the Ecological Research Committee/ NFR. No. 17, modern methods in the study of microbial ecology

24. Zimmerman R, Meyer-Reil L (1974) A new method for fluorescence staining of bacterial populations on membrane filters. Kiel Meeresforsch 30:24-27

25. Hobbie JE, Daley RJ, Jasper S (1977) Use of nuclepore filters for counting bacteria by fluorescence microscopy. Appl Environ Microbiol 33(5):1225-1228

26. Mercier F, Glorennec P, Thomas O, Le Bot B (2011) Organic contamination of settled house dust, a review for exposure assessment purposes. Environ Sci Technol 45(16):6716-6727

27. Government DocumentHealth and Safety Executive (2000) General methods for sampling and gravimetric analysis of respirable, thoracic and inhalable aerosols 14/3. Her Majesty's Stationary Office, Norwich

28. La Guardia MJ, Hale RC (2015) Halogenated flame-retardant concentrations in settled dust, respirable and inhalable particulates and polyurethane foam at gymnastic training facilities and residences. Environ Int 79:106-114

29. Cao Z, Yu G, Chen Y, Liu C, Liu K, Zhang T, Wang B, Deng S, Huang J (2013) Mechanisms influencing the BFR distribution patterns in office dust and implications for estimating human exposure. J Hazard Mater 252-253:11-18

30. Yang YY, Liu LY, Xiong YY, Zhang GM, Wen HM, Lei J, Guo LL, Lyu YL (2016) A comparative study on physicochemical characteristics of household dust from a metropolitan city and a remote village in China. Atmos Pollut Res 7(6):1090-1100

31. Yu Y, Yang D, Wang X, Huang N, Zhang X, Zhang D, Fu J (2013) Factors influencing on the bioaccessibility of polybrominated diphenyl ethers in size-specific dust from air conditioner filters. Chemosphere 93(10):2603-2611

32. Molhave L, Schneider T, Kjaergaard SK, Larsen L, Norn S, Jorgensen O (2000) House dust in seven Danish offices. Atmos Environ 34(28):4767-4779

33. Woldemichael MH (2012) The mineralogical composition of house dust in Ontario, Canada, in Department of Earth Sciences. Thesis. University of Ottawa: Ottawa. Canada

34. Lanzerstorfer C (2017) Variations in the composition of house dust by particle size. J Environ Sci Health Part A Tox Hazard Subst Environ Eng 52(8):770-777

35. Yoshinaga J, Yamasaki K, Yonemura A, Ishibashi Y, Kaido T, Mizuno K Takagi M, Tanaka A (2014) Lead and other elements in house dust of Japanese residences - source of lead and health risks due to metal exposure. Environ Pollut 189:223-228

36. Cesari D, Contini D, Genga A, Siciliano M, Elefante C, Baglivi F, Daniele L (2012) Analysis of raw soils and their re-suspended PM10 fractions: characterisation of source profiles and enrichment factors. Appl Geochem 27(6):1238-1246

37. Rintala H, Pitkaranta M, Taubel M (2012) Microbial communities associated with house dust. Adv Appl Microbiol 78(78):75-120

38. Zhang H, Xie J, Yoshino H, Yanagi U, Hasegawa K, Kagi N, Lian Z (2016) Thermal and environmental conditions in Shanghai households: risk factors for childhood health. Build Environ 104:35-46

39. Karkkainen PM, Valkonen M, Hyvarinen A, Nevalainen A, Rintala H (2010) Determination of bacterial load in house dust using $\mathrm{QPCR}$, chemical markers and culture. J Environ Monit 12(3):759-768
40. Raffy G, Mercier F, Blanchard O, Derbez M, Dassonville C, Bonvallot N, Glorennec P, Le Bot B (2017) Semi-volatile organic compounds in the air and dust of 30 French schools: a pilot study. Indoor Air 27(1):114-127

41. Bergh C, Torgrip R, Emenius G, Ostman C (2011) Organophosphate and phthalate esters in air and settled dust-a multi-location indoor study. Indoor Air 21(1):67-76

42. Garcia M, Rodriguez I, Cela R (2007) Microwave-assisted extraction of organophosphate flame retardants and plasticizers from indoor dust samples. J Chromatogr A 1152(1-2):280-286

43. Van den Eede N, Dirtu AC, Neels H, Covaci A (2011) Analytical developments and preliminary assessment of human exposure to organophosphate flame retardants from indoor dust. Environ Int 37(2):454-461

44. Dirtu AC, Ali N, Van den Eede N, Neels H, Covaci A (2012) Country specific comparison for profile of chlorinated, brominated and phosphate organic contaminants in indoor dust. Case study for Eastern Romania, 2010. Environ Int 49:1-8

45. Brommer S, Harrad S, Van den Eede N, Covaci A (2012) Concentrations of organophosphate esters and brominated flame retardants in German indoor dust samples. J Environ Monit 14(9):2482-2487

46. Ali N, Dirtu AC, Van den Eede N, Goosey E, Harrad S, Neels H, t Mannetje A, Coakley J, Douwes J, Covaci A (2012) Occurrence of alternative flame retardants in indoor dust from New Zealand Indoor sources and human exposure assessment. Chemosphere 88(11):1276-1282

47. Bi CY, Maestre JP, Li HW, Zhang G, Givehchi R, Mandavi A, Kinney KA, Siegel J, Horner SD, Xu Y (2018) Phthalates and organophosphates in settled dust and HVAC filter dust of US low-income homes: association with season, building characteristics, and childhood asthma. Environ Int 121:916-930

48. Araki A, Saito I, Kanazawa A, Morimoto K, Nakayama K, Shibata E, Tanaka M, Takigawa T, Yoshimura T, Chikara H et al (2014) Phosphorus flame retardants in indoor dust and their relation to asthma and allergies of inhabitants. Indoor Air 24(1):3-15

49. Abdallah MA, Covaci A (2014) Organophosphate flame retardants in indoor dust from Egypt. Environ Sci Technol 48(9):4782-4789

50. Kim JW, Isobe T, Sudaryanto A, Malarvannan G, Chang KH, Muto M, Prudente M, Tanabe S (2013) Organophosphorus flame retardants in house dust from the Philippines: occurrence and assessment of human exposure. Environ Sci Pollut Res 20(2):812-822

51. Ali N, Ali L, Mehdi T, Dirtu AC, Al-Shammari F, Neels H, Covaci A (2013) Levels and profiles of organochlorines and flame retardants in car and house dust from Kuwait and Pakistan: implication for human exposure via dust ingestion. Environ Int 55:62-70

52. Peng CF, Tan HL, Guo Y, Wu Y, Chen D (2017) Emerging and legacy flame retardants in indoor dust from East China. Chemosphere 186:635-643

53. Dahlberg A-K, Weiss JM (2016) Organophosphorus flame retardants in Swedish house dust. Organohalogen Compd 78:1174-1177

54. Wong F, de Wit CA, Newton SR (2018) Concentrations and variability of organophosphate esters, halogenated flame retardants, and polybrominated diphenyl ethers in indoor and outdoor air in Stockholm, Sweden. Environ Pollut 240:514-522

55. World Health Organization (2000) Environmental Health Criteria 218. http:// www.inchem.org/documents/ehc/ehc/ehc218.htm. Accessed 20 Apr 2019

56. Marklund A, Andersson B, Haglund P (2003) Screening of organophosphorus compounds and their distribution in various indoor environments. Chemosphere 53(9):1137-1146

57. van der Veen I, de Boer J (2012) Phosphorus flame retardants: properties, production, environmental occurrence, toxicity and analysis. Chemosphere 88(10):1119-1153

58. Meeker JD, Stapleton HM (2010) House dust concentrations of organophosphate flame retardants in relation to hormone levels and semen quality parameters. Environ Health Perspect 118(3):318-323

59. Guo HY, Zheng XB, Ru SL, Sun RX, Mai BX (2019) Size-dependent concentrations and bioaccessibility of organophosphate esters (OPEs) in indoor dust: a comparative study from a megacity and an e-waste recycling site. Sci Total Environ 650:1954-1960

\section{Publisher's Note}

Springer Nature remains neutral with regard to jurisdictional claims in published maps and institutional affiliations. 